\title{
A TEORIA DO DESENVOLVIMENTO DESIGUAL E COMBINADO NOS MUNICÍPIOS PRODUTORES DE PETRÓLEO E GÁS DAS REGIÕES NORTE FLUMINENSE E BAIXADAS LITORÂNEAS
}

\section{UNEVEN AND COMBINED DEVELOPMENT THEORY IN THE MUNICIPALITIES OF NORTE FLUMINENSE AND BAIXADAS LITORÂNEAS REGIONS}

\author{
Juliana Higa Bellini \\ Universidade Federal de Viçosa (UFV), Viçosa, MG, Brasil, julianahbellini@gmail.com \\ Ítalo Caixeiro Stephan \\ Universidade Federal de Viçosa (UFV), Viçosa, MG, Brasil, stephan@ufv.br
}

\begin{abstract}
RESUMO
A exploração de petróleo e gás na Bacia de Campos - RJ desencadeou uma série de transformações nos municípios das regiões Norte Fluminense - RJ e Baixadas Litorâneas - RJ, causada pela inserção nos modernos circuitos de produção globalizados que aplicam nesses municípios referenciais produtivos e econômicos extralocais. Estas transformações levaram a formação de uma nova região denominada região produtiva de petróleo e gás, cuja definição parte da conformação do circuito espacial produtivo com foco nas mudanças sócioespaciais provocadas pela inserção econômica. A aplicação das teorias de desenvolvimento desigual e combinado de Trotsky e de espaço derivado de Milton Santos sobre a região produtiva de petróleo e gás permitiu o reconhecimento de relações subordinadas que, atreladas à proposta de desenvolvimento local, são insuficientes para provocar o desenvolvimento e a transformação social nessa região produtiva, dada as condições econômicas mundiais e de atuação de um Estado orientado para o contínuo acúmulo de capital. Recomenda-se, assim, que sejam fortalecidas as especificidades locais e ações no sentido de cooperação intermunicipal, sobretudo entre os municípios produtores de petróleo e gás das regiões Norte Fluminense e Baixadas Litorâneas.
\end{abstract}

Palavras-chave: Municípios produtores de petróleo e gás; Desenvolvimento desigual e combinado; Desenvolvimento local; Região produtiva; Circuitos espaciais produtivos.

\begin{abstract}
The oil and gas exploration in the North Fluminense - RJ and Baixadas Litorâneas - RJ regions, in state of Rio de Janeiro, trigged a series of transformations in the municipalities of these regions, caused for insertion in the modern globalized production circuits that apply in these territories productive and economic extra-local references. These transformations resulted in a new productive area called productive area of oil and gas. Reading these transformations came from analysis of productive space circuits, focusing on the socio-spatial changes caused by economic insertion, where uneven and combined development theory by Trotsky and derivatives spaces theory by Milton Santos allowed the acknowledgment of subordinate relationships that linked with the proposal local development, are insufficient to induce development and social transformation in this productive areas, because the economic global conditions and the State are oriented to continuous capital accumulation. The local specificities are recommended.
\end{abstract}

Keywords: Oil and gas Municipalities; Uneven and combined development; Local development; Productive area; productive spatial circuits.

Artigo recebido para publicação em junho de 2014

Artigo aceito para publicação em agosto de 2015

\section{INTRODUÇÃO}

O petróleo, como uma commodity, é um recurso natural que tem sua gestão, exploração, distribuição e comercialização relacionadas à escala internacional, ainda que no Brasil seja um recurso nacionalizado. 
Piquet (2007, p. 24) explica que "Dada a importância da indústria do petróleo para qualquer país (...) sua influência dificilmente irá limitar-se a espaços subnacionais.”.

No Brasil, a gestão do petróleo depende de capitais nacionais e internacionais, sobretudo após 1997 (Lei Federal nº 9.478/97), quando a Petrobrás perdeu o monopólio e o país se abriu para o mercado estrangeiro. Desse modo, os municípios produtores de petróleo e gás ficaram sujeitos ao regime do capital nacional e internacional.

A sujeição ao capital internacional foi possível pela atuação de um Estado que buscou e busca se inserir economicamente nos modernos circuitos de produção globalizados e que, para isso, sujeita seus recursos naturais ao controle externo.

Com a globalização, o país busca tornar-se viável ao enraizamento dos grandes capitais. Adaptam-se as condições de regulação da economia e do território e, paralelamente, dá-se um esforço pra reequipar algumas áreas. Assim, holdings nacionais e globais irão desenhar suas topologias no território brasileiro (...). (SANTOS E SILVEIRA, 2006, p. 109).

Cano (2011, p. 36) ensina que a condição econômica submetida ao controle externo, isto é, subordinada, foi potencializada a partir da década de 1990, quando se implantou reformas neoliberais no país que incluíram, entre outras demandas, adequar a economia nacional aos interesses do capital financeiro internacional, a abertura comercial e a diminuição do papel do Estado no planejamento e regulamentação da economia.

Nesse cenário neoliberal, os governos municipais ganharam destaque com a emergência de uma nova escala de gestão territorial sob a proposta de desenvolvimento local. Nesta proposta, os governos dos municípios produtores de petróleo e gás passaram a ser protagonistas de seu desenvolvimento e a se sujeitar às forças econômicas e políticas exógenas que gestionam o espaço produtivo. "A cidade se dobra a essa demanda [da produção], se reforma, se reorganiza, se refaz, se cria.” (SANTOS, 1993, p. $123)$. 
A sujeição a forças extralocais repercute no desenvolvimento de relações competitivas entre os municípios e na criação de especialidades à serviço da indústria de petróleo e gás, na medida em que os municípios se esforçam para se inserirem na cadeia produtiva petrolífera.

Os municípios produtores de petróleo e gás das regiões Norte Fluminense e Baixadas Litorâneas exercem distintas funções na cadeia produtiva petrolífera. Os municípios de Macaé e Campos dos Goytacazes, por exemplo, são respectivamente a sede do parque industrial petrolífero e sede de instituições educacionais que formam os trabalhadores para a indústria de petróleo e gás.

Embora esses papéis estejam distribuídos entre os municípios produtores, eles não são naturalmente determinados, em outras palavras, significa dizer que nem sempre a função que determinado município exerce na indústria de petróleo e gás está relacionada às características físicas presentes, mas relaciona-se às vantagens que o município oferece para que os investimentos e os empreendimentos se estabeleçam ali e não em outro lugar.

Brito (2007) explica que a produção de vantagens que diferenciam os lugares é fundamental para o desenvolvimento capitalista, posto que a desigualdade entre lugares produz vantagens comparativas para o capital.

(...) estabelece-se um verdadeiro certame de localização, em uma interminável contenda por estabelecer a posição máxima na gradação de ofertas tributárias, de terras e infraestruturas. O receptor das benesses (a grande empresa) é quem determina o final do torneio e define o vitorioso da guerra entre lugares. (BRANDÃO apud PIQUET, 2007, p. 27).

O exemplo do município de Rio das Ostras, localizado na região Baixadas Litorâneas, é esclarecedor. Exercendo a função de domiciliar os trabalhadores da indústria de petróleo e gás, o município também investe em um bairro industrial na divisa com o município de Macaé a fim de atrair novos empreendimentos e capturar os investimentos.

Por outro lado, a produção de diferenciações faz emergir novas desigualdades sócio-espaciais, a competitividade e a fragmentação territorial. Os municípios, ao estabelecerem relações de concorrência 
por investimentos e pela localização dos empreendimentos, passam a direcionar os recursos públicos em condições favoráveis à fixação do capital em seu território, como serviços e infraestrutura, isenções fiscais, etc. A produção de condições favoráveis ao capital é proporcional à capacidade financeira do município para realizar investimentos e, no caso dos municípios produtores de petróleo e gás, relaciona-se ao valor do repasse de royalties ${ }^{1}$ e à função que o município exerce e deseja exercer dentro da cadeia produtiva petrolífera.

Esses investimentos públicos, por sua vez, passam a diferenciar os lugares e a desenvolver desigualdades sócio-espaciais entre os municípios produtores de petróleo e gás. Por fim, dá-se a fragmentação territorial, quando a competição pela localização de empreendimentos e pelos investimentos pressiona os municípios em relações de divergência de interesses, sem perspectivas de cooperação intermunicipal.

Nesse cenário, a teoria de desenvolvimento desigual e combinado, descrita por Trotsky em 1906 para compreender o capitalismo no início do século XX, explica que a produção de condições favoráveis à fixação do capital e, em última instância, de desigualdades entre os espaços produtivos, é uma condição fundamental para o poder de barganha dos empreendimentos e de acúmulo de capital.

Assim, ainda que os municípios produtores de petróleo e gás componham o mesmo espaço dinamizado pela indústria de petróleo e gás, não resultam em um conjunto de municípios que trabalham juntos, que compartilham interesses e projetos de desenvolvimento que poderiam ser comuns, tendo em vista 0 ambiente de elevada competitividade, fragmentação territorial e o processo de acumulação de capital.

\section{A REGIÃO PRODUTIVA}

\footnotetext{
${ }^{1}$ A título explicativo, royalties são compensações financeiras pagas pelas concessionárias exploradoras de petróleo e gás à União, que repassa aos municípios, como compensação pelos impactos ambientais causadas pela atividade exploratória.
} 
O conceito de região está relacionado à necessidade de compreender o espaço por suas diferenças e similaridades. A partir da identificação de aspectos comuns entre os lugares são estabelecidos recortes que, por sua vez, definem as regiões, como por exemplo, as regiões naturais compostas pela uniformidade dos elementos naturais, como relevo, clima e vegetação.

Desse modo, pode ser constituída uma variedade de regiões para atender aos contextos no qual o conceito de região serve como unidade explicativa, como o contexto político, econômico, cultural e natural.

No caso de região produtiva, o recorte espacial parte da identificação das etapas e dos agentes envolvidos na produção, desde a matéria-prima, o beneficiamento, a distribuição e a comercialização.

A análise de uma região produtiva, segundo Castillo e Frederico (2010), pode ser realizada de dois modos, por meio da cadeia produtiva que foca na organização empresarial; ou por meio do circuito espacial produtivo com foco no espaço geográfico.

A análise pela cadeia produtiva tem como objetivo organizar as atividades empresariais e torná-las mais produtivas com base em fundamentos da administração, economia e engenharia de produção, direcionado a potencializar os efeitos da divisão do trabalho, do desenvolvimento local e da competitividade.

Já a análise da região produtiva pelo circuito espacial produtivo parte do espaço geográfico como materialização da inserção de determinado espaço na cadeia produtiva, isto é, trata-se “(...) das implicações sócio-espaciais da adaptação de lugares, regiões e territórios aos ditames da competitividade (...)" (CASTILLO E FREDERICO, 2010, p. 468). Na adaptação ao sistema produtivo, inclui-se também o Estado, a sociedade e o sistema econômico. 
Com a internacionalização do capital, as análises sobre a região produtiva se tornaram mais complexas e dinâmicas, pois as relações entre os espaços produtivos passaram a serem, ao mesmo tempo, concentradas nos centros do sistema econômico e político mundial e distribuídas segundo a divisão internacional do trabalho.

Para entender esse cenário, o conceito de região produtiva adquiriu uma nova escala, capaz de abranger uma área maior, nem sempre contínua e homogênea (SANTOS, 1993). A região produtiva passou a ser definida “(...) como o resultado das possibilidades ligadas a certa presença (...) de capitais fixos exercendo determinado papel ou determinadas funções técnicas e das condições do seu funcionamento econômico (...)" (SANTOS, 2012, p. 90). Em outras palavras, a região produtiva pode ser entendida como o conjunto de espaços onde se realiza determinada atividade produtiva, que os organiza segundo suas necessidades e estabelece um sistema de relações entre os territórios que dão suporte à produção.

No que tange os municípios produtores de petróleo e gás das regiões Norte Fluminense e Baixadas Litorâneas, a análise pela cadeia produtiva já foi realizada por Piquet (2010) que pode, inclusive, determinar os gargalos do sistema produtivo que impedem a expansão da produção de petróleo e gás.

Nesse sentido, esse artigo trata da análise da região produtiva pelo circuito espacial produtivo, a fim de identificar como a inserção na economia de petróleo e gás tem afetado os municípios produtores, sobretudo no que tange as condições de governança.

\section{A região produtiva de petróleo e gás}

No planejamento e gestão do estado do Rio de Janeiro há duas principais divisões regionais, a estabelecida pelo Instituto Brasileiro de Geografia e Estatística - IBGE e a do governo do Estado. Entretanto, no contexto da internacionalização do capital e da exploração de petróleo e gás, essas divisões regionais não são representativas para os municípios das regiões Norte Fluminense e Baixadas Litorâneas, quando um novo recorte regional se faz necessário para explicar as relações 
estabelecidas entre os municípios, configurando um novo grupo de municípios que representa a região produtiva de petróleo e gás.

No contexto econômico e produtivo das regiões Norte Fluminense e Baixadas Litorâneas, a região produtiva de petróleo e gás é definida pelo conjunto de municípios produtores de petróleo e gás e que, por sua vez, faz parte da Organização dos Municípios Produtores de Petróleo e Gás - OMPETRO. A organização foi criada em 2001, com o objetivo de defender os interesses de seus componentes, os municípios Armação de Búzios, Arraial do Cabo, Cabo Frio, Campos dos Goytacazes, Carapebus, Casimiro de Abreu, Macaé, Quissamã, Rio das Ostras e São João da Barra.

Se na região de governo do Estado o Norte Fluminense é composto pelos municípios Campos dos Goytacazes, Carapebus, Cardoso Moreira, Conceição de Macabu, Macaé, Quissamã, São Fidélis, São Francisco de Itabapoana e São João da Barra, na região produtiva de petróleo e gás alguns municípios foram excluídos, pois suas participações são secundárias no contexto da exploração petrolífera, conforme representação na figura 1, que sobrepõe a composição regional do governo do Estado e a região produtiva de petróleo e gás.

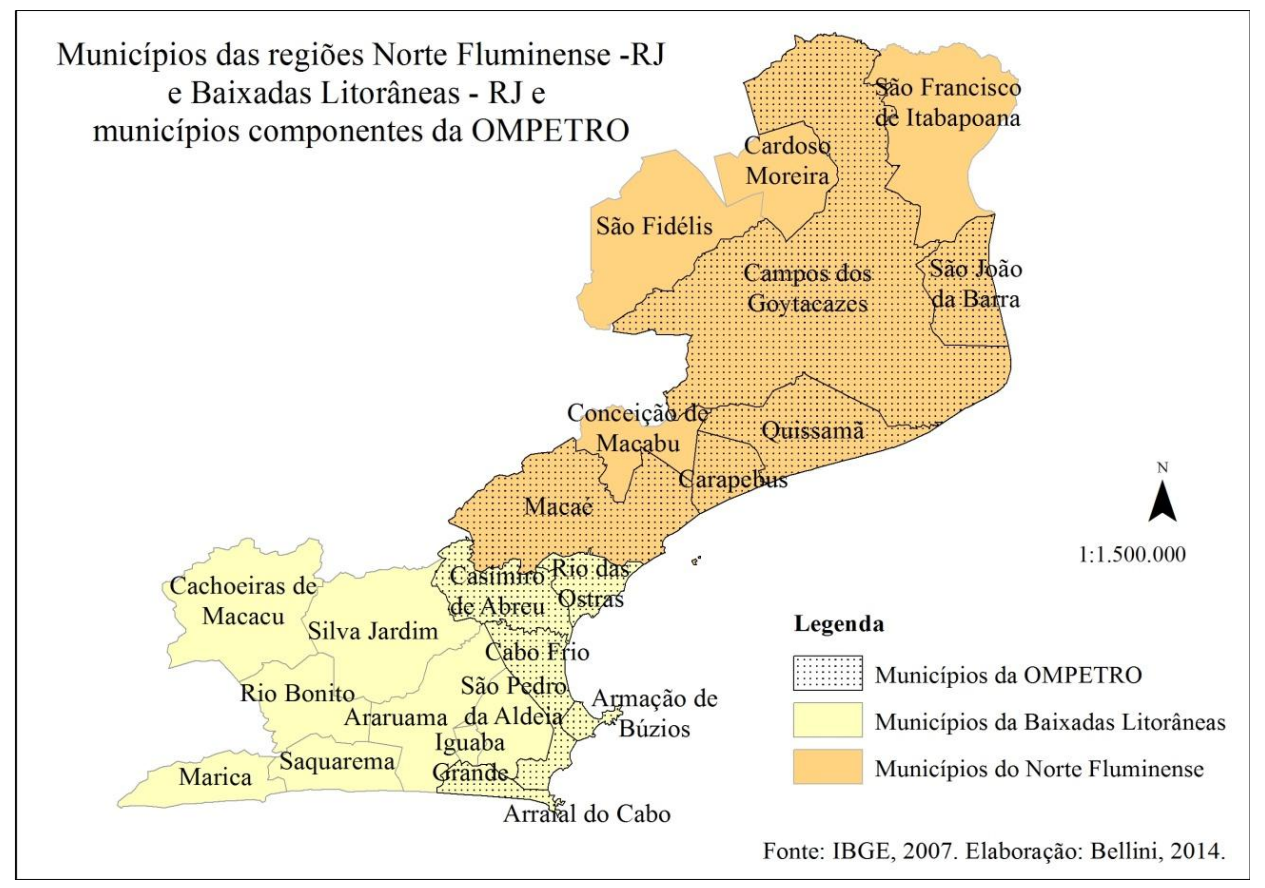

Figura 1. Mapa dos municípios das regiões Norte Fluminense e Baixadas Litorâneas e os municípios componentes da OMPETRO. 
Na figura 1 verifica-se que a região produtiva de petróleo e gás, formada pelos municípios que compõem a OMPETRO, representa uma composição de municípios das regiões Norte Fluminense e Baixadas Litorâneas.

Os municípios da região produtiva de petróleo e gás se destacam por dois aspectos: pela atividade que exercem na cadeia produtiva petrolífera e pelos elevados royalties que recebem. Todos os municípios da região produtiva de petróleo e gás pertencem a Zona de Produção Principal (ZPP) - composta pelos municípios produtores de petróleo e gás ou que possuem instalações industriais ou atividades de apoio à exploração. Por formarem a ZPP, esses municípios recebem os maiores repasses de royalties.

O repasse de royalties é distribuído proporcionalmente à produção dos poços de petróleo que cabe a cada município. Os poços são divididos entre os municípios por meio das linhas paralelas e ortogonais definidas pelo Instituto Brasileiro de Geografia e Estatística - IBGE, como mostra a figura 2, onde os pontos brancos representam os poços petrolíferos.

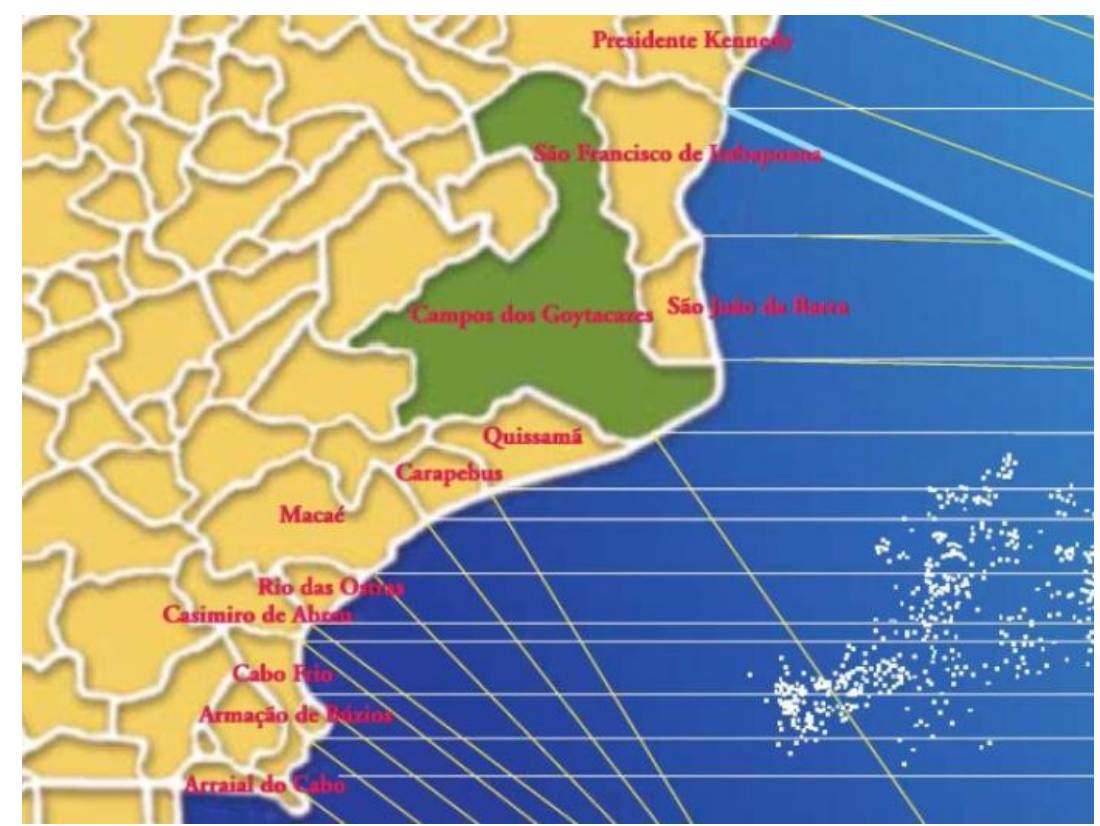

Figura 2. Linhas ortogonais e paralelas para definição do repasse de royalties. Fonte: ANP (2003). 
Torna-se importante dizer que os royalties também são pagos aos municípios que são atravessados por oleodutos ou gasodutos e outras estruturas de escoamento da produção petrolífera, compondo a Zona de Produção Secundária (ZPS); e aos municípios que fazem fronteira com a ZPP ou que sofrem as consequências econômicas e sociais da atividade petrolífera, formando a Zona Limítrofe (ZL).

Dados da ANP (2015) apresentam recorde na produção de petróleo e gás no Brasil, como mostra a figura 3, com destaque para o Estado do Rio de Janeiro (Tabela 1) e para a Bacia de Campos, com a maior produção de petróleo entre os bacias produtoras (Tabela 2).

O Estado do Rio de Janeiro respondeu por $67 \%$ da produção de petróleo e $36,1 \%$ da produção de gás natural, muito embora não seja o Estado com maior número de campos produtores (o Estado do Rio de Janeiro possui 46 campos produtores, enquanto a Bahia possui 84 campos produtores) (ANP, 2015). Já a Bacia de Campos foi responsável por 72,1\% da produção de petróleo e 32,1\% da produção de gás do Rio de Janeiro (ANP, 2015).

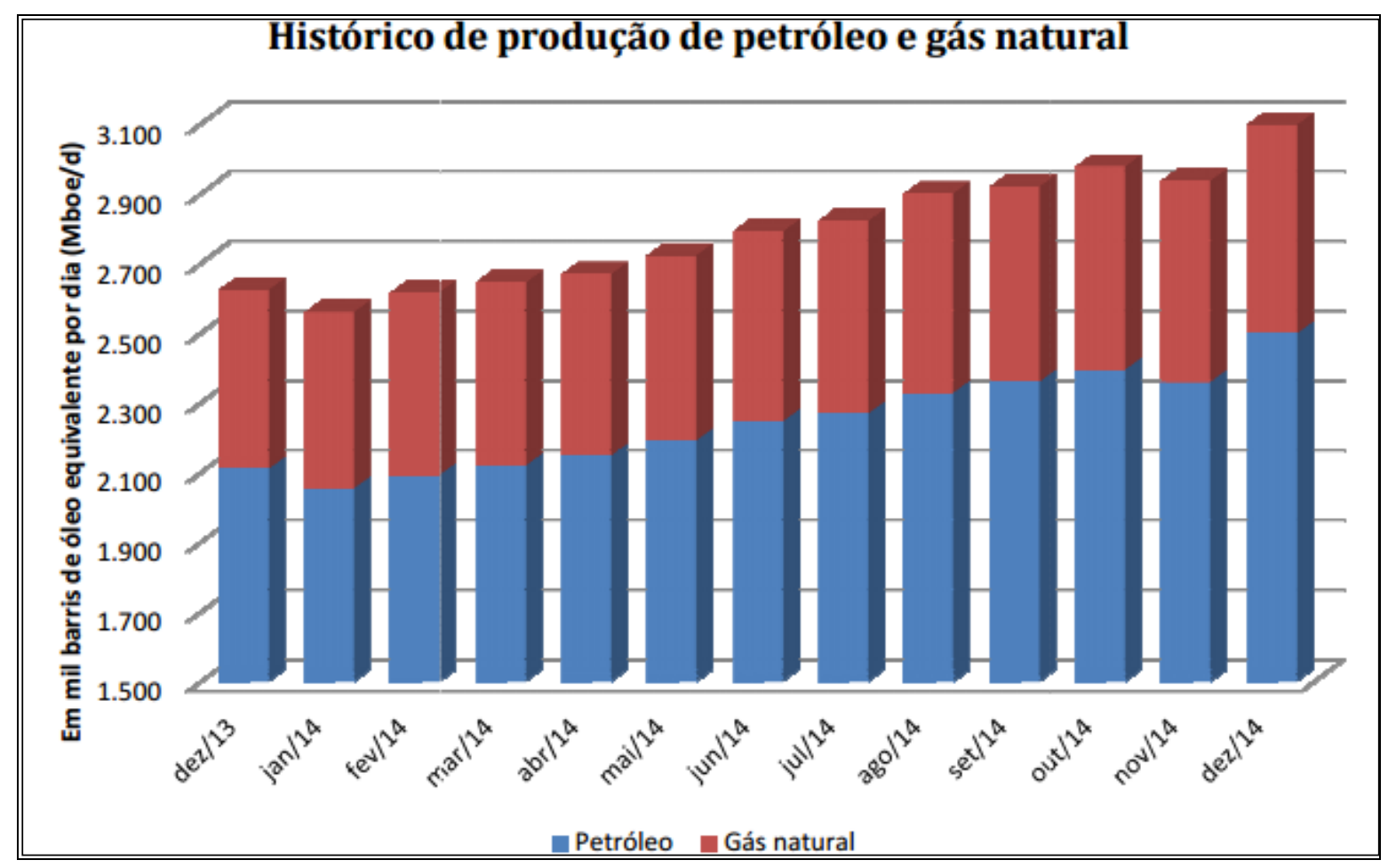

Figura 3. Histórico de produção de petróleo e gás natural no Brasil entre 2013 e 2014.

Fonte: ANP, 2015. 


\begin{tabular}{ccc}
\hline Estado & Produção total (boe/d*) & No de campos produtores \\
\hline Rio de Janeiro & 1.889 .443 & 46 \\
Espírito Santo & 514.443 & 46 \\
São Paulo & 311.093 & 5 \\
Amazonas & 112.216 & 6 \\
Bahia & 96.843 & 84 \\
Rio Grande do Norte & 64.643 & 82 \\
Sergipe & 57.556 & 22 \\
Maranhão & 29.892 & 1 \\
Alagoas & 11.292 & 11 \\
Ceará & 8.290 & 6 \\
Total geral & 3.095 .711 & 309 \\
\hline
\end{tabular}

Tabela 1. Distribuição da produção de petróleo e gás por Estado.

*Barris de óleo equivalente (1.000m3 de gás $\approx 6,29$ barris), por dia. Fonte: ANP, 2015.

\begin{tabular}{ccc}
\hline Bacia & Produção total (boe/d*) & No de campos produtores \\
\hline Campos & 1.992 .720 & 48 \\
Santos & 657.915 & 9 \\
Solimões & 112.216 & 6 \\
Potiguar & 66.247 & 84 \\
Espírito Santo & 64.343 & 40 \\
Recôncavo & 59.122 & 77 \\
Sergipe & 57.556 & 22 \\
Camamu & 37.227 & 3 \\
Parnaíba & 29.892 & 1 \\
Alagoas & 11.292 & 11 \\
Ceará & 6.686 & 4 \\
Tucano Sul & 494 & 4 \\
Total geral & 3.095 .711 & 309 \\
\hline
\end{tabular}

Tabela 2. Distribuição da produção de petróleo e gás por Bacia.

*Barris de óleo equivalente (1.000m3 de gás $\approx 6,29$ barris), por dia. Fonte: ANP, 2015.

Devido à alta produção de petróleo e gás na Bacia de Campos, os municípios recebedores de royalties, sobretudo da ZPP, apresentaram elevados repasses de recursos, como mostra a Tabela 3, onde Campos dos Goytacazes se sobressaiu com o maior volume de royalties em 2014. 
Tais valores de repasse de royalties repercutem no Produto Interno Bruto (PIB) desses municípios.

Em 2010, sete municípios da ZPP estiveram entre os 100 maiores PIBs per capita municipal do Brasil, como mostra a Tabela 4 (IBGE, 2010).

\begin{tabular}{cccc}
\hline Município & Zona & Valor (R\$) & Valor (\%) \\
\hline Campos dos Goytacazes & ZPP & $632.820 .616,41$ & 27,9 \\
Macaé & ZPP & $491.526 .473,38$ & 21,7 \\
Cabo Frio & ZPP & $197.868 .413,00$ & 8,7 \\
Rio das Ostras & ZPP & $189.794 .271,44$ & 8,3 \\
Maricá & ZPP & $137.585 .295,52$ & 6,0 \\
São João da Barra & ZPP & $126.233 .541,62$ & 5,5 \\
Quissamã & ZPP & $87.778 .296,94$ & 3,8 \\
Casimiro de Abreu & ZPP & $77.476 .949,22$ & 3,4 \\
Armação de Búzios & ZPP & $72.488 .760,97$ & 3,2 \\
Arraial do Cabo & ZPP & $45.041 .384,09$ & 1,9 \\
Cachoeiras de Macacu & ZPS & $43.539 .622,52$ & 1,9 \\
Carapebus & ZPP & $39.533 .371,64$ & 1,7 \\
Silva Jardim & ZPS & $39.035 .978,70$ & 1,7 \\
Saquarema & ZL & $15.815 .871,44$ & 0,7 \\
Araruama & ZL & $10.872 .449,73$ & 0,4 \\
São Pedro da Aldeia & ZL & $10.300 .006,78$ & 0,4 \\
Rio Bonito & ZL & $9.156 .175,39$ & 0,4 \\
São Francisco de Itabapoana & ZL & $8.870 .044,88$ & 0,3 \\
São Fidélis & ZL & $8.583 .914,41$ & 0,3 \\
Conceição de Macabu & ZL & $7.439 .065,95$ & 0,3 \\
Iguaba Grande & ZL & $7.438 .701,85$ & 0,3 \\
Cardoso Moreira & ZL & $6.294 .870,47$ & 0,2 \\
\hline
\end{tabular}

Tabela 3. Valores de royalties para os municípios das regiões Norte Fluminense e Baixadas Litorâneas em 2014 Fonte: Inforoyalties - UCAM, a partir de dados da ANP, 2014.

\begin{tabular}{cccc}
\hline Município & Posição & PIB per capita & População \\
\hline Quissamã & $9^{\underline{0}}$ & $153.769,95$ & 20.244 \\
São João da Barra & $17^{0}$ & $106.348,05$ & 332.767 \\
Carapebus & $33^{0}$ & $83.859,53$ & 13.348 \\
Rio das Ostras & $71^{0}$ & $57.882,81$ & 105.676 \\
Campos dos Goytacazes & $74^{\underline{0}}$ & $54.607,81$ & 463.545 \\
Macaé & $76^{0}$ & $54.501,02$ & 206.748 \\
Casimiro de Abreu & $99^{\circ}$ & $48.517,35$ & 35.373 \\
\hline
\end{tabular}

Tabela 4. Municípios das regiões Norte Fluminense e Baixadas Litorâneas com os maiores PIBs per capita nacional - 2010 Fonte: IBGE (2010). 
Assim, no contexto da exploração de petróleo e gás, as divisões regionais estabelecidas são anacrônicas e vão de encontro à composição da região produtiva de petróleo gás. Nesse contexto, a região produtiva torna-se mais adequada, pois pode explicar as novas relações entre os municípios produtores e estabelecer a relação que cada lugar passa a ter com a demanda econômica de sua região.

A região produtiva é também mais adequada no contexto da exploração de petróleo e gás por definir um recorte espacial que considera a capacidade econômica dos municípios, tendo em vista que os municípios da ZPP têm maiores condições de realizar investimentos e, consequentemente, maior poder de competir pela localização de empreendimentos e de investimentos.

Do ponto de vista do planejamento regional, a configuração segundo a região produtiva também colabora na definição de um planejamento e no desenvolvimento de projetos direcionados aos interesses de municípios sob o mesmo contexto econômico, social e político relacionado, no caso relacionado à exploração de petróleo e gás.

\section{O ESPAÇO DERIVADO E O DESENVOLVIMENTO DESIGUAL E COMBINADO NOS TERRITÓRIOS DO PETRÓLEO}

Por ser uma commodity, o petróleo é negociado nos mercados internacionais e os critérios de produção não são estabelecidos localmente, isto é, nos espaços produtivos. A esses, cabe se adequarem à forma $\mathrm{e}$ à produtividade estabelecidas internacionalmente, conformando os espaços derivados.

Os espaços derivados possuem uma autonomia relativa, posto que suas formas e funções são definidas externamente, ou seja, pelas economias dominantes. Para Santos (2009) os países subdesenvolvidos ${ }^{2}$ são, sobretudo, espaços derivados. Moraes (2005) explica que a formação dos espaços derivados no Brasil existe desde o período colonial. Com a conjuntura neoliberal, esses espaços foram atualizados sob um novo arranjo do sistema econômico internacional a explorar o mundo subdesenvolvido.

\footnotetext{
${ }^{2}$ Neste artigo, optou-se pelo uso do conceito subdesenvolvimento por considerarmos que a posição de país subdesenvolvido não é um estágio da trajetória de desenvolvimento, mas uma condição estrutural no capitalismo.
} 
Para a formação dos espaços derivados, a participação do Estado em consonância com as necessidades do setor privado é fundamental, permitindo que os espaços produtivos sejam moldados pela eficácia da produtividade, onde os investimentos e as políticas públicas, bem como a organização do território, estão direcionados às melhores condições produtivas para a acumulação de capital. Assim, concorda-se com Corrêa (1993, p. 26) que entende que a atuação do Estado “(...) se faz, fundamentalmente e em última análise, visando criar condições de realização e reprodução da sociedade capitalista.”.

\section{A escala local no conceito de desenvolvimento desigual e combinado}

Com as políticas neoliberais no país desde a década de 1990, a escala do desenvolvimento local surgiu na gestão territorial com a função de fortalecer as relações de competitividade das atividades econômicas e entre os espaços produtivos (FUINI, 2011), ao mobilizar recursos naturais, culturais e econômicos específicos da escala local para uma articulação à lógica do capital.

Para Maricato (2006), a escala local foi um importante passo para a economia global por permitir que empresas multinacionais ou transnacionais passassem a firmar contratos sem a intermediação de outros níveis federados.

Assim, o desenvolvimento local objetiva atingir um nível ótimo de competitividade que reforce a coesão econômica e social, onde os governos locais tenham autonomia para oferecer vantagens logísticas e de infraestrutura para o processo produtivo e garantir uma posição no mercado globalizado (SILVEIRA, 2008; FUINI, 2011).

Para a efetividade do desenvolvimento local e o atendimento das exigências na escala econômica internacional, ocorreram mudanças na governança e na gestão econômica, tais como a:

- Flexibilização dos processos produtivos com crescente especialização

- Descentralização política, econômica e financeira

- Redefinição do papel do Estado e maior responsabilidade para as instâncias locais 
- Competitividade inter-regional

- Promoção de diferenciais, com ênfase na inovação tecnológica

Todavia, do ponto de vista da análise do circuito espacial produtivo, não se pode considerar que haja de fato desenvolvimento local, sendo somente a realização da acumulação de capital na periferia do sistema, sem espaço para construção do desenvolvimento ou transformação social (SILVEIRA, 2008).

Nesse cenário, a gestão territorial voltada para o desenvolvimento local repete a teoria do desenvolvimento desigual e combinado descrita por Trotsky para explicar as relações estabelecidas entre países desenvolvidos e subdesenvolvidos que, com a internacionalização do capital e as políticas neoliberais, foram aplicadas em uma perspectiva multiescalar.

\section{O desenvolvimento desigual e combinado na região produtiva}

Inicialmente, a teoria do desenvolvimento desigual e combinado teve como objetivo compreender a relação entre países desenvolvidos e subdesenvolvidos, entendendo que não há um processo evolutivo em que um país atrasado passe a ser um país de vanguarda, pois, ainda que se modernize e se desenvolva, não pode atingir o mesmo patamar dos países desenvolvidos.

Essa teoria entende que o papel desempenhado pelos países subdesenvolvidos na economia mundial é crucial para a manutenção e crescimento econômico e social dos países desenvolvidos.

Nesse sentido, entende-se que no contexto da internacionalização do capital as relações desiguais também ocorrem na escala subnacional, sobretudo com o destaque dado a escala local. "As mudanças espaciais com a globalização da economia parecem desmistificar a ideia de homogeneização do espaço, apontando para novas desigualdades e fragmentações." (PIRES, 2006, p. 48). 
Assim, do mesmo modo que entre os países desenvolvidos e subdesenvolvidos, a desigualdade nas diferentes escalas espaciais é fundamental para o desenvolvimento privado e acúmulo de capital e, em última instância, do capitalismo em países subdesenvolvidos.

Sob o capitalismo dependente, a persistência de formas econômicas arcaicas não é uma função secundária e suplementar. A exploração dessas formas, e sua combinação com outras, mais ou menos modernas e até ultramodernas, fazem parte do 'cálculo capitalista'. (FERNANDES, 1968, p.64).

Assim, o atrasado, o arcaico, não são formas indesejadas, mas são economicamente necessárias e complementares às formas mais modernas.

Por isso, concorda-se com Oliveira (1985, p. 89) que entende que não há diferentes "Brasis" quando se trata da diferenciação econômica entre regiões no Brasil. "Ressalve-se aqui (...) que não se encampa nem se trabalha sobre uma dualidade ou multiplicidade de 'Brasis' (...). Esses 'Brasis' não são mais que a força diferenciada da expansão do capitalismo.”.

Na região produtiva de petróleo e gás as formas menos desenvolvidas podem ser lidas nos municípios menos dinamizados por essa indústria, sobretudo nos municípios que compõem as ZPS e ZL, enquanto as formas ultramodernas são presentes principalmente nos municípios da ZPP e são materializadas em multinacionais ou transnacionais, como Shell, Exxon e Petrobras (PIQUET, 2010).

Para Holland (1976 apud EGLER, 2007), o poder dessas empresas é tão expressivo que a localização delas “(...) é capaz de proteger ou aumentar a participação no mercado nacional através de aumentos de escala, inovações ou táticas de formação de preços interfirmas.” (HOLLAND, 1976 apud EGLER, 2007, p. 219-220). Por isso, a vantagem locacional que as empresas da indústria de petróleo e gás podem proporcionar se torna tão atrativa para os governos locais.

A condição de desigualdade combinada resulta na especialização dos espaços produtivos e na competitividade em diferentes escalas espaciais, inclusive dentro da região produtiva. 
$\mathrm{Na}$ indústria de petróleo e gás, essa desigualdade é relativa. Ainda que os investimentos e os empreendimentos dessa indústria tenham mobilidade espacial, o recurso natural é fixo. Desse modo, o comportamento locacional da indústria de petróleo e gás responde pela presença da matéria-prima e não por medidas atrativas, embora haja alguma mobilidade possível entre os municípios produtores, uma vez que são os locais mais próximos dos pontos de exploração (PIQUET, 2007).

Entretanto, os governos locais continuam a buscar uma posição diferenciada na cadeia produtiva de petróleo e gás, como Campos dos Goytacazes que passou a investir em instituições educacionais que formassem a mão-de-obra qualificada que a indústria de petróleo e gás exige, ou os municípios que recebem a indústria para-petrolífera, procurando oferecer vantagens a esse setor.

\footnotetext{
Nas práticas administrativas públicas locais, por desconhecimento ou má fé, são concedidos os mais variados benefícios a empresas fornecedoras, sob o argumento de se criar 'atratividades' para a sua localização. (PIQUET, 2007, p. 27).
}

O fato dos empreendimentos da indústria de petróleo e gás desencadearem o crescimento econômico local e gerarem emprego e renda é supervalorizado, ignorando o peso das exigências e das concessões. Ignora-se também que os segmentos mais lucrativos dessa indústria trabalham em outra escala, muitas vezes em regiões políticas e economicamente centrais ou mesmo no exterior (GUSMÃO et al., 2013, p. $11)$.

Assim, embora a consideração de Piquet (2007) sobre o comportamento locacional da indústria de petróleo e gás seja válida, assiste-se a um movimento contrário, pois,

(...) os espaços não se diferenciam mais sobre a base de seu estoque de capital, mas em função das aptidões produtivas de sua força de trabalho, e de sua aptidão em conceber bens novos e produtos técnicos mais avançados. (EGLER, 2007, p. 217)

Essa competitividade surge até mesmo entre os municípios da OMPETRO, pois, como explica Piquet (2010), a organização concentra os esforços basicamente para a garantia do repasse dos royalties, sem dar atenção para a promoção do desenvolvimento local. 
Torna-se importante considerar que o desenvolvimento local especializado, embora seja atrativo em termos econômicos, fragiliza as economias locais e as torna vulneráveis às oscilações do valor do produto no mercado, especialmente quando se trata do petróleo e gás, cujos preços são definidos no mercado internacional e são recursos finitos.

No caso dos municípios produtores de petróleo e gás da região produtiva em questão, a primeira consequência trazida pelo desenvolvimento da economia petrolífera foi a competitividade pelos royalties, que resultou em um processo de desmembramento de antigos municípios e criação de cinco novos municípios (PIQUET, 2007), sendo eles Quissamã e Cardoso Moreira, emancipados em 1989; Rio das Ostras emancipado em 1992 e; Armação de Búzios, Carapebus e São Francisco de Itabapoana, emancipados em 1995.

A partir da década de 1980, a competitividade municipal foi intensificada com a Constituição Federal de 1988 que deu maior autonomia administrativa aos municípios e com a Lei Federal nº 9.478/97, conhecida como Lei do Petróleo, que ampliou o valor do repasse de royalties aos municípios produtores e afetados pela economia do petróleo e gás.

Desse modo, a competitividade local impede a construção de iniciativas de cooperação e coordenação que possam apoiar medidas de transformação social e desenvolvimento dentro da região produtiva. Predomina, como descreve Gusmão (2010, p. 35),

(...) a visão intramuros, localista, setorial (...). Cada município (seus recursos e problemas) é tratado como um caso diferente e isolado, desconsiderando-se a necessidade-oportunidade de projetar cenários futuros a partir de um foco estratégico que favoreça um diálogo mais generoso entre o local e o regional (...).

\section{PROPOSIÇÕES}

Para Gusmão et al. (2013, p. 11), o grande desafio do desenvolvimento local é a transformação dos recursos específicos em ativos que visem uma condição econômica menos dependente e direcionada para a transformação social. No caso dos municípios produtores de petróleo e gás, uma política de 
desenvolvimento local também deve incluir o desenvolvimento de alternativas econômicas que visem à era pós-petróleo.

Entretanto, ainda mantêm-se práticas avessas à cooperação e coordenação, sobretudo porque a competitividade e a produção de diferenciações espaciais são características da proposta de desenvolvimento local e fundamentais para ampliação do acúmulo de capital.

Assim, a característica de competitividade segue contrária ao que se entende por uma política de desenvolvimento local e regional ideal, isto é, que identifique e invista em oportunidades produtivas diversificadas, que sejam independentes da atividade petrolífera e estabeleçam relações cooperativas entre os entes federados (PIQUET, 2012), sobretudo, que crie relações de complementaridade produtiva entre os municípios que compõem essas regiões (NAZARETH, 2011).

Para Egler (2007, p. 209), a questão do desenvolvimento e transformação social depende da atuação do Estado, "na medida em que a resolução passa necessariamente pela composição do bloco no poder e pelas medidas de políticas públicas que afetam a economia nacional e a distribuição territorial da renda." e, Fuini (2011) inclui uma questão de abrangência multiescalar, uma vez que nenhuma escala contém em si a capacidade para regular todos os fluxos econômicos.

Pires (2006) ressalta a necessidade de desenvolver especificidades territoriais, isto é, o estabelecimento e fortalecimento de uma diferença entre os territórios que não esteja associada á disponibilidade de incentivos ou a possibilidade de mobilidade dos agentes econômicos. Silveira (2008, p. 62) explica que quando foca-se no desenvolvimento de especificidades territoriais,

\footnotetext{
A questão primária do desenvolvimento local deixa de ser uma relação oferta-demanda e passa a ser o relacionamento entre o conjunto de capacidades e recursos que se constituem como ativos ou fatores de desenvolvimento.
}

Nesse sentido, a promoção do desenvolvimento e da transformação social depende da apropriação pela população dos valores contidos no lugar, de modo que esses valores sejam revertidos em benefícios no 
seu lugar de origem (MORAES, 2005) e não externamente, como bem fundamentado pelas teorias dos espaços derivados e do desenvolvimento desigual e combinado. Além disso, faz-se necessário o desenvolvimento de criatividades locais, que destaquem as singularidades de cada local (CASTRO, 2005), daquilo que não possa simplesmente ser repetido, pois esta intimamente atrelado à determinado lugar.

A manutenção de condições mais de especialidade e menos de especificidade permite somente a permanência da concorrência e da competição para hangariar vantagens locacionais e investimentos e, em última instância, da fragmentação do território.

Por isso, na medida em que o espaço produtivo nacional se mantiver subordinado às condições do capital globalizado e sob a gestão de um estado-facilitador do capital (GUSMÃO et al., 2013), os benefícios para o desenvolvimento e transformação social serão, na melhor das hipóteses, pontuais e não duráveis.

\section{CONSIDERAÇÕES FINAIS}

O presente artigo buscou um exercício analítico de ler as teorias do espaço derivado de Milton Santos e do desenvolvimento desigual e combinado de Trotsky na realidade da região produtiva de petróleo e gás e sob a ótica do circuito espacial produtivo.

Esse exercício experienciou a mudança da escala mundial e nacional para a subnacional com as políticas neoliberais a partir da década de 1990, buscando um encadeamento na proposta de desenvolvimento local.

Na efetivação do desenvolvimento local como espaço produtivo, o Estado surge com um papel ativo de incluir novas escalas produtivas nos fluxos globais, aumentando as condições de especialização e competição entre os lugares, inclusive entre membros da mesma região produtiva. 
Nas regiões Norte Fluminense e Baixadas Litorâneas, a materialização da teoria do desenvolvimento desigual e combinado se revela na competitividade entre os municípios afetados pela exploração petrolífera, sobretudo entre os municípios pertencentes à Zona de Produção Principal, que detém maiores recursos para realizar investimentos atrativos para o capital e, consequentemente, maior poder no jogo pela fixação de capitais. Para se inserirem competitivamente, esses municípios se especializam em determinadas funções na cadeia produtiva de petróleo e gás, e acabam por produzir a desigualdade espacial intermunicipal. Tal condição repercute na fragmentação territorial, onde os municípios da região produtiva de petróleo e gás encontram dificuldades na organização de iniciativas cooperativas.

Por fim, as conclusões consideraram que as práticas competitivas e de desigualdade espacial impossibilitam as políticas de desenvolvimento e transformação social, na medida em que são produzidas mais especialidades que especificidades, bem como a fragmentação territorial e, por isso, viabilizam o desenvolvimento local de acordo com a lógica da cadeia produtiva.

\section{REFERÊNCIAS}

AGÊNCIA NACIONAL DO PETRÓLEO - ANP. Impactos sociais do desenvolvimento da atividade de exploração e produção de petróleo nas regiões das Baixadas Litorâneas e do Norte Fluminense. Nota técnica 13/2003. Rio de Janeiro: Projeto CTPETRO - Tendências Tecnológicas, 2003. 49p.

AGÊNCIA NACIONAL DO PETRÓLEO - ANP. Boletim da produção de petróleo e gás natural. Dezembro, 2014. Superintendência de Desenvolvimento e Produção - SDP. 1 fevereiro 2015. Disponível em: < http://www.anp.gov.br/?dw=73964>. Acesso em 06 de abril de 2015.

BRASIL. Lei Federal n. 9.478, de 6 de agosto de 1997. Dispõe sobre a política energética nacional, as atividades relativas ao monopólio do petróleo, institui o Conselho Nacional de Política Energética e a Agência Nacional do Petróleo e dá outras providências. Disponível em <http://www.planalto.gov.br/ccivil_03/leis/19478.htm>. Acesso em 11 de janeiro de 2014.

BRITO, Thiago Macedo Alves de. A metamorfose do conceito de região: leituras de Milton Santos. GEOgraphia, Rio de Janeiro, vol.10, n.20, p.74-105. 2008. Disponível em < http://www.uff.br/geographia/ojs/index. php/geographia/article/view Article/268>. Acesso em 22 de abril de 2014.

CANO, Wilson. Novas determinações sobre a questão regional e urbana após 1980. Revista Brasileira de Estudos Urbanos e Regionais, Rio de Janeiro, v.13, n.2, p.27-53, nov. 2011.

CASTILLO, Ricardo; FREDERICO, Samuel. Espaço geográfico, produção e movimento: uma reflexão sobre o conceito de circuito espacial produtivo. Sociedade \& Natureza, Uberlândia, v.22, n.3, p.461-474, dez. 2010. 
CASTRO, Demian Garcia. Desenvolvimento, políticas públicas e regionalização: algumas reflexões a partir do território fluminense. In: Encontro de Geógrafos da América Latina, 10., 2005, São Paulo. Anais... São Paulo, USP, 2005.

CORRÊA, Roberto Lobato. O Espaço urbano. $2^{a}$ ed. São Paulo: Editora Ática, 1993. 96p.

EGLER, Cláudio Antonio Gonçalves. Questão regional e gestão do território no Brasil. P. 207-238. In: CASTRO, Iná Elias de; GOMES, Paulo Cesar da Costa; CORRÊA, Roberto Lobato (Orgs). Geografia: conceitos e temas. $15^{\mathrm{a}}$ ed. Rio de Janeiro: Bertrand Brasil, 2007. 352p.

FERNANDES, Florestan. Sociedade de classes e subdesenvolvimento. $4^{\mathrm{a}}$ ed. Rio de Janeiro: Zahar, 1968. 253p.

FUINI, Lucas Labigalini. Desenvolvimento e arranjos produtivos locais: concepções e interrelações. Revista Geografia, Londrina, v.20, n.2, p.151-164, maio/ago. 2011.

GUSMÃO, Paulo Pereira de. Apropriação e ordenamento territorial na zona costeira do Estado do Rio de Janeiro: Grandes corporações ou as políticas públicas? Revista Brasileira de Estudos Urbanos e Regionais, v.12, n.2, p. 23-37. Nov. 2010.

GUSMÃO, Paulo Pereira de; SANTOS, Bianca Borges Medeiros; ZANI, Maíra Vieira. Gestão territorial na zona costeira do sudeste brasileiro e a geografia da cadeia produtiva do petróleo. In. ENCONTRO DE GEÓGRAFOS DA AMÉRICA LATINA, XIV, 8 a 12 de abril de 2013, Lima, Peru. Anais...,Lima, 2013, p. 1-19.

INSTITUTO BRASILEIRO DE GEOGRAFIA E ESTATÍSTICA - IBGE. Produto interno bruto dos municipios 2010. IBGE: 2010. Disponível em: <http://www.ibge.gov.br/home/estatistica/economia/pibmunicipios/2010/default_xls.shtm>. Acesso em: 12 de abril de 2013.

MARICATO, Ermínia. Posfácio. In: DAVIS, Mike. Planeta Favela. Tradução de Beatriz Medina. 1ª ed. São Paulo: Boitempo, 2006. 272p.

MORAES, Antonio Carlos Robert de. Meio ambiente e ciências humanas. $4^{\mathrm{a}}$ ed. ampliada. São Paulo: Annablume, 2005. $162 \mathrm{p}$.

NAZARETH, Paula Alexandra. Municípios do estado do Rio de Janeiro: prosperidade em perspectiva ou riscos à frente? P. 255-273. In: URANI, André; GIAMBIAGI, Fabio (Org.). Rio: A hora da virada. Rio de Janeiro: Elsevier, 2011. 304p.

OLIVEIRA, Francisco de. Elegia para uma re(li)gião: SUDENE, nordeste: Planejamento e conflito de classes. $4^{\mathrm{a}}$ ed. Rio de Janeiro: Paz e Terra, 1985. 137p.

PIQUET, Rosélia. Indústria do petróleo e dinâmica regional: reflexões teórico-metodológicas. P. 15-33. In: PIQUET, Rosélia; SERRA, Rodrigo. (Orgs). Petróleo e região no Brasil: o desafio da abundância. $1^{\text {a }}$ ed. Rio de Janeiro: Garamond, 2007. 351p.

PIQUET, Rosélia. A cadeia produtiva do petróleo no Brasil e no Norte Fluminense. Revista de Desenvolvimento Econômico, Salvador, ano XIII, n. 22, p. 19-27. Dez. 2010.

PIQUET, Rosélia. O lugar do regional na indústria do petróleo. Revista Brasileira de Estudos Urbanos e Regionais, v.14, n.1, p.51-63, maio 2012.

PIRES, Elson Luciano Silva. Mutações econômicas e dinâmicas territoriais locais: delineamento preliminar dos aspectos conceituais e morfológicos. P. 48-70. In: SPOSITO, Eliseu Savério; SPOSITO, Maria Encarnação Beltrão; SOBARZO, Oscar Cidades médias: Produção do espaço urbano e regional. 1ª ed. São Paulo: Expressão Popular, 2006. 376p.

SANTOS, Milton. A Urbanização brasileira. São Paulo, Editora Hucitec, 1993. 157p. 
SANTOS, Milton. [1985]. Espaço e método. $5^{\mathrm{a}}$ ed.1 $1^{\mathrm{a}}$ reimpressão. São Paulo: Editora da Universidade de São Paulo, 2012. $120 \mathrm{p}$.

SANTOS, Milton. [1971]. O Trabalho do Geógrafo no Terceiro Mundo. $5^{\mathrm{a}}$ ed. São Paulo: Editora da Universidade de São Paulo, 2009. 136p.

SANTOS, Milton; SILVEIRA, Maria Laura. Brasil: território e sociedade no início do século XXI. 9ª ed. Rio de Janeiro: Record, 2006. 473p.

SILVEIRA, Caio. Desenvolvimento local e novos arranjos socioinstitucionais: algumas referências para a questão da governança. P. 41-65. In: DOWBOR, Ladislau. (Org.). Politicas para o desenvolvimento local. $1^{\text {a }}$ ed. São Paulo: Editora Fundação Perseu Abramo, 2008. 400p.

UNIVERSIDADE CÂNDIDO MENDES - UCAM. Inforoyalties. Disponível em: < http://royaltiesdopetroleo.ucamcampos.br/>. Acesso em: 17 de março de 2015. 